\title{
Organic Arsenical Exposure Stimulates Atherosclerosis through Oxidative Stress Increase and Adhesion Molecule Expression
}

\author{
Afeez Adekunle Ishola ${ }^{1}$, Norlelawati A.Talib ${ }^{1}$, Naznin Muhammad ${ }^{1}$, Zunariah Buyong ${ }^{1}$, Abdul Hadi Mohamed ${ }^{1}$, \\ Yiyi Myint ${ }^{1}$, Niza Samsuddin ${ }^{2}$, Radiah Abdul Ghani ${ }^{2}$, Norzamzila Abdullah ${ }^{1^{*}}$ \\ ${ }^{1}$ Kulliyyah of Medicine, International Islamic University Malaysia, Jalan Indera Mahkota 2, 25200, Kuantan, Pahang, Malaysia . \\ ${ }^{2}$ Kulliyyah of Allied Health Sciences, International Islamic University Malaysia, Jalan Indera Mahkota 2, 25200, Kuantan, Pahang, Malaysia.
}

\begin{tabular}{|c|c|}
\hline ARTICLE INFO & ABSTRACT \\
\hline $\begin{array}{l}\text { Article history: } \\
\text { Received on: } 30 / 06 / 2016 \\
\text { Revised on: } 26 / 07 / 2016 \\
\text { Accepted on: } 03 / 09 / 2016 \\
\text { Available online: } 29 / 11 / 2016\end{array}$ & $\begin{array}{l}\text { Approximately } 100 \text { million people are exposed to arsenic worldwide, majorly through drinking water and } \\
\text { anthropogenic activities. Monosodium methylarsonate (MSMA) is a potent organoarsenical content of } \\
\text { herbicides used in many Asian countries. Epidemiological studies have linked inorganic arsenic exposure with } \\
\text { atherosclerosis, whereas organoarsenicals toxicological studies are scanty. Paraoxonase } 1 \text { (PON1) enzyme } \\
\text { suppresses systemic Ox-LDL generation, thereby preventing atherosclerosis. We investigated effects of MSMA }\end{array}$ \\
\hline $\begin{array}{l}\text { Key words: } \\
\text { Atherosclerosis, Organic } \\
\text { arsenic, Monosodium } \\
\text { methylarsonate (MSMA), } \\
\text { Paraoxonase } 1 \text { (PON1), Lipid } \\
\text { peroxidation, adhesion } \\
\text { molecules (VCAM-1 and } \\
\text { ICAM-1). }\end{array}$ & $\begin{array}{l}\text { oral exposure on PONI, lipid peroxidation and atherosclerosis development. Five groups (n=11) of Sprague- } \\
\text { Dawley rats received daily intubation of MSMA at } 0 \text { (control), 42.1, 63.2, 126.4 and } 210.7 \mathrm{mg} / \mathrm{kg} \text { BW } \\
\text { respectively for } 16 \text { weeks. Serum samples were analysed for PON } 1 \text { activities, Ox-LDL and MDA levels. } \\
\text { Histomorphometric evaluation (H\&E and VVG) and immunohistochemistry (VCAM-1 and ICAM-1) were done } \\
\text { on aorta. High mortality rate led to discontinuation of } 126.4 \text { and } 210.7 \mathrm{mg} / \mathrm{kg} \mathrm{BW} \text { treatment groups. Groups } \\
\text { treated with } 42.1 \text { and } 63.2 \mathrm{mg} / \mathrm{kg} \mathrm{B.W.} \mathrm{MSMA} \mathrm{had} \mathrm{a} \mathrm{significantly} \mathrm{higher} \mathrm{MDA} \mathrm{(p=0.004,CI:} 2.73-0.82 \text { ) and } \\
\text { Ox-LDL (p<0.0001,CI: } 2425.07-955.45 \text { ) levels but lower PON1:Ox-LDLratio (p<0.0001,CI: } 0.49-1.07 \text { ) } \\
\text { compared to control. Microscopically, treatment groups showed early atherosclerotic intima thickening and } \\
\text { positive VCAM-1 and ICAM-1 expressions. In conclusion, chronic MSMA exposure reduced PON1 ability to } \\
\text { hydrolyse Ox-LDL and also induced inflammation by elevating oxidative stress that supports early } \\
\text { atherosclerosis development. }\end{array}$ \\
\hline
\end{tabular}

\section{INTRODUCTION}

Health challenges associated with chronic and acute exposure to arsenic (As) have drawn attentions around the world (Hughes et al., 2011; Bolt, 2012; Chen et al., 2013). Agricultural practices have been identified to contribute immensely towards increasing arsenic exposure above normal healthy range in our environment (Garelick et al., 2008; Bolt, 2013). MSMA is an organic form of arsenic used as active ingredient of some herbicides and pesticides for controlling weeds and insects in crops and non-crops areas worldwide particularly in Asian

* Corresponding Author

Norzamzila Abdullah, Kulliyyah of Medicine, International Islamic University Malaysia, Jalan Indera Mahkota 2, 25200, Kuantan, Pahang, Malaysia.Email: norzamzila@gmail.com countries (Arnold et al., 2003; Albert et al., 2008; Morrissey et al., 2008; Hammid et al., 2013). Humans are exposed to the toxicity of arsenic mainly via drinking water and anthropogenic activities. It is evident that various side effects of MSMA has been described in earlier studies which include hepatocellular damage, renal toxicity, neurological problems as well as skin problems (Hessl and Berman, 1982; De Capitani et al., 2005; Yao et al., 2013; Casale et al., 2014). Atherosclerotic disorders have been linked to lipid peroxidation (Kei, 1978). On the same note, epidemiological studies have also established a link between high-chronic inorganic arsenic exposure with cardiovascular diseases such as stroke, coronary artery disease (CAD) and peripheral arterial disease (Stea et al., 2014; Samsuddin et al., 2015). Previous study also reported that inorganic arsenic induces atherosclerosis and endothelial dysfunction in experimental rats (Lee et al., 2002). 
However, studies focusing on the adverse effects of organic arsenic are limited (Kato et al., 2010; Hammid et al., 2013; Ong et al., 2013). PON1 is a lactonase cardio-protective enzyme that hydrolyses ox-LDL and prevents oxidation of LDL (Aviram et al., 1998; Hao et al., 2013). PON1 is also associated with HDL and plays a vital role in suppressing ox-LDL-generated inflammation on arterial endothelium that can initiate atherosclerosis (Eckerson et al., 1983; Gan et al., 1991; Durrington et al., 2001; Efrat and Aviram, 2010). However, literature on organic arsenicals' effect on PON1 does not exist to the best of our knowledge. To bridge this literary deficiency, our study investigated popular agriculturally used organic arsenic (MSMA) oral exposure on PON1 activity, lipid peroxidation and atherosclerosis development in rat model.

\section{MATERIAL AND METHODS}

\section{Animal housing and materials}

Male Sprague-Dawley rats of approximately 250g, 3-4 months old, were purchased from Animal breeding centre, Universiti Putra Malaysia, Selangor. Animals were housed in polypropylene cages, two animals per cage, in Kulliyyah of Medicine, IIUM animal retention facility. They were exposed to 12 hours light and dark cycle at $25^{\circ} \mathrm{C}$ throughout the study. The rats were allowed access to standard rat chow (Gold Coin, Malaysia) and reverse osmosis (RO) water (ELGA Prime system, USA) ad libitum.

Animals were allowed to acclimatize for one week in our animal retention area after which blood sample was taken through orbital sinus from all the animals, under inhalation anaesthesia, for the pre-treatment serum sample isolation. Then the animals were divided into five groups randomly. These groups include control group, treatment 1(T1), 2(T2), 3(T3) and 4(T4) groups. Research planning and protocols were approved by International Islamic University Malaysia (IIUM) Institutional Animal Care and Use Committee (IACUC) with approval number IIUM/IACUC Approval/2014/ (3)(11). Study was performed humanely in accordance to IACUC guidelines. MSMA was purchased from Ancom Corp (Malaysia) and all other chemicals used were analytical grade supplied by Mercks (Germany) or Sigma (Texas) chemicals except stated otherwise.

\section{Dose Planning and Sample Collection}

To the best of our knowledge after extensive search, no previous academic toxicology study of MSMA on murine exists. Hence, our dose planning was done using the toxicity information on the chemical data sheet (CDS) of the product published by the manufacturer, Ancom Corp; in addition to the reported inorganic arsenic contamination doses within the south Asian countries (Nordstrom, 2002). Ancom Corp reported $1264 \mathrm{mg} / \mathrm{Kg}$ as the $\mathrm{LD}_{50}$ of MSMA for rats (Ancom, 2012). Previous study reported drinking water iAs contamination of up to $5000 \mu \mathrm{g} / \mathrm{L}(5 \mathrm{mg} / \mathrm{L})$ for Thailand and up to $100,000 \mu \mathrm{g} / \mathrm{L}(100 \mathrm{mg} / \mathrm{L})$ for USA and Canada (Nordstrom, 2002). Meanwhile, daily adult human water consumption is approximately 4 litres (Sawka et al., 2005). Therefore, our chosen doses were calculated to simulate a real life arsenic exposure as reported in previous studies (Nordstrom, 2002). Fifty five male Sprague-Dawley rats were divided into five groups $(n=11)$ including a control group. Treatment groups 1, 2, 3 and 4 were given oral intubation of 42.13, 63.30, 126.40 and $210.67 \mathrm{mg} / \mathrm{kg}$ body weight of MSMA respectively daily for 16 weeks, which is equivalent to $1 / 30,1 / 20,1 / 10$ and $5 / 30 \mathrm{LD}_{50}$ of MSMA for rat reported by Ancom, (2012) and it also mimic the calculated daily drinking water arsenic exposure for some South Asian countries (Thailand) and some other countries (USA and Canada) around the world (Nordstrom, 2002, Ilyaset al., 2009, Ancom, 2012). Pre and post treatment blood samples were collected into plain tubes through orbital sinus under inhalation anesthesia for serum isolation.

\section{Biochemical tests}

Serum PON1 activities, paraoxonase and arylesterase were determined after hydrolysis of paraoxon and phenylacetate substrates respectively. Serum paraoxonase activity measured the rate of phenol production after hydrolysis by paraoxon as described by Eckerson et al. (1983). Molar extinction coefficient of $18290 \mathrm{M}^{-1} \mathrm{~cm}^{-1}$ (Eckerson et al., 1983) was used to calculate activity. Arylesterse activity was carried out according to Gan et al. (1991) method. MDA was determined spectrophotometrically by TBARS assay as described by Kie, (1978) and Ox-LDL level was measured following Ox-LDL ELISA kit SEA527Ra (CloudClone Corp, Houston, TX) manufacturer's instruction.

\section{Aorta Histomorphometric Assessment}

Formalin (10\%) fixed aorta samples were processed and embedded in parafin. Aorta sections $(4 \mu \mathrm{m})$ were microscopically evaluated after staining with Haematoxylin and Eosin (H\&E) using manual protocol. In order to precisely view the position of the internal elastic lamina (IEL) of the aorta, elactic fibre assessment was done by carrying out Verhorff Van Gieson (VVG) staining using connective tissue staining kit, ab150667 from Abcam (Cambridge, U.K). Immunohistochemistry (IHC) was performed to assess the expression of adhesion molecule and early inflammatory markers VCAM-1 and ICAM-1 using Dako autostainer and EnVision+System-HRP(DAB) kit with rabbit antibody (Carpinteria, CA, USA). VCAM-1 and ICAM-1 antibodies were diluted to 1:200 and 1: 150 respectively for IHC.

\section{Statistical Analysis \\ Normality of data was determined by Kolmogrov- smirnov test. ANOVA was used to test parametric data of PON1 activities, oxLDL, PON1:Ox-LDL ratio and MDA levels between the study groups. Non-parametric data were tested using Kruskal- walis test. Paired t-test was also used to test between pre and post treatment measurements for normally distributed data while Friedman's test was used for non-normally distributed data. All analysis was performed using IBM SPSS version 21 . $\mathrm{P}<0.05$ was chosen to be statistically significant at $95 \%$ confidence interval.}




\section{RESULTS}

\section{Clinical Signs and Mortality}

Generally, the most common clinical signs observed at the beginning of the study in most of the treatment groups were diarrhea and weight fluctuation. These signs automatically alleviated or stopped, without any intervention, within few days in MSMA treated groups 1 (T1) and 2 (T2) that were given 42.13 and $63.20 \mathrm{mg} / \mathrm{kg}$ body weight MSMA respectively. However mortality was recorded in MSMA treated groups 3 and 4 that were administered with 126.4 and $252.8 \mathrm{mg} / \mathrm{Kg} \mathrm{BW}$. The mortality was associated with severe diarrhea and drastic weight decrease in both groups. Calculated mortality rate were 0.636 and 0.545 for groups 3 and 4 respectively. Therefore, treatment was discontinued for animals in groups 4 by fifth week and group 5 by second week because of the high mortality rate recorded in those groups. Control group animals were consistent in growth and did not show any sign of diarrhea.

\section{Body and organ weight}

The weight trend of each group is presented in Figure 1. Comparing the MSMA treated groups with Control group, there was a mean weight decrease of $10.36 \%$ in Treatment group 1 (42.13mg/Kg BW MSMA) while Treatment group 2 (63.20 mg/Kg BW MSMA) recorded reduction of $5 \%$ in its mean weight at week 16. There was no statistical significance in mean relative organ weight (defined as organ weight/body weight) for liver $(\mathrm{p}=0.761)$, kidney $(\mathrm{p}=0.684)$ and heart $(\mathrm{p}=0.379)$. A reduction of $17 \%$ and $8 \%$ was detected in actual mean weight of heart and kidney respectively in Treatment group 1 when compared to that of Control group. Tables 1 and 2 present actual organ weight and relative organ weights in detail.

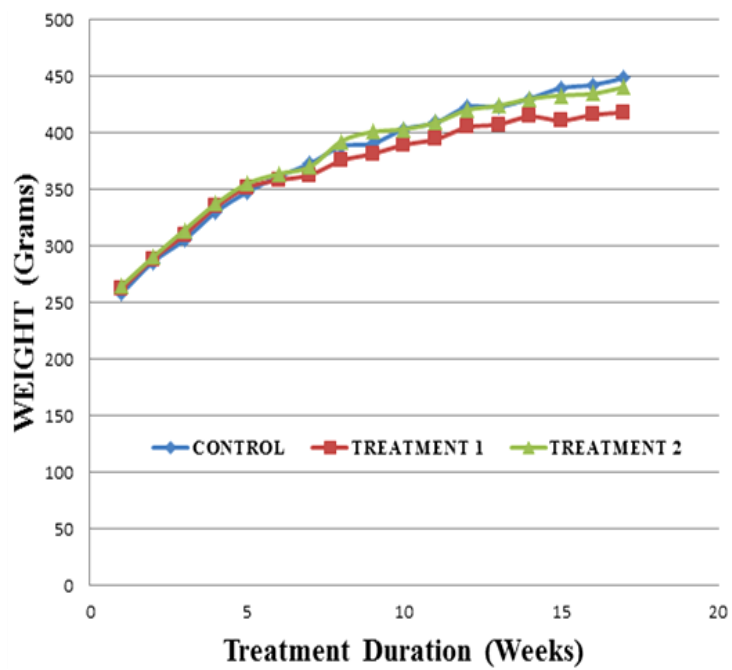

Fig. 1: Mean Weight Trend in Control and MSMA Treated Group.

\section{Serum Paraoxonase 1 (PON 1) Activities}

After 16 weeks of MSMA treatment, Treatment group 1 has $50.91 \%$ increase in mean PON1 activity as compared to that of Control group, while PON1 activity in Treatment group 2 was decreased by $4.378 \%$ compared to Control. There were no significant difference $(\mathrm{p}=0.097)$ in mean arylesterase activities between Control and MSMA treated groups (Table 3). Although insignificant ( $p>0.05)$, comparing PON1 activity between pre and post treatment in each group, paraoxonase activity in Control group increased by $19.32 \%$ which is higher increment as compared to $6.82 \%$ increase recorded in Treatment group 1 . On the other hand, Treatment group 2 recorded a decrease in paraoxonase activity after MSMA treatment by $5.86 \%$ (Figure 2). Likewise, arylesterase was also insignificant $(\mathrm{p}>0.05)$ after comparing pre and post MSMA treatment in each group (figure 3). The arylesterase activity in Control group was reduced by $0.3 \%$ and arylesterase activity in MSMA treated groups 1 and 2 increased by $4.7 \%$ and $16.4 \%$ respectively.

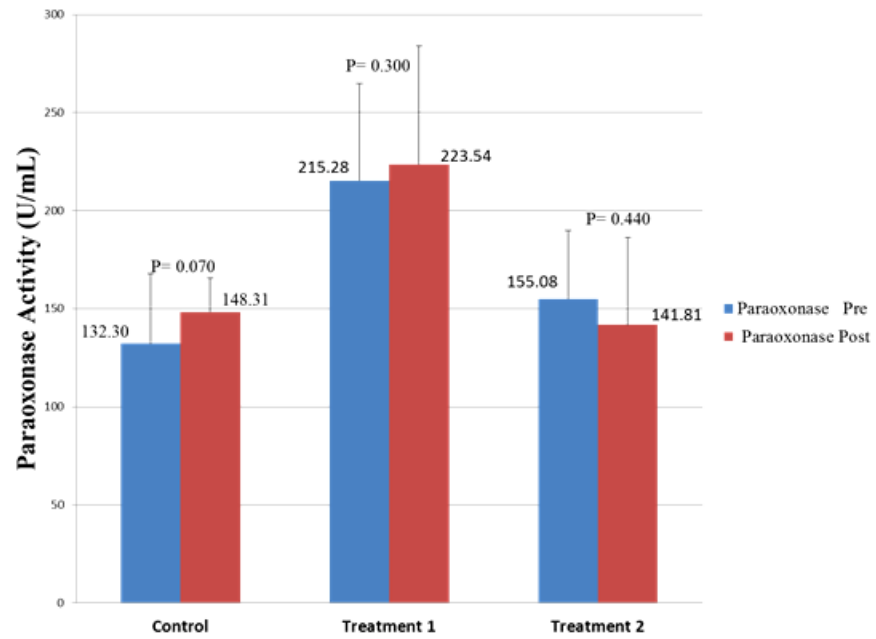

Fig. 2: Comparison of Serum Paraoxonase Activity during pre and post MSMA treatment. Results presented as mean $(\mathrm{SD})$. Paired t-test. $\mathrm{P}<0.05$ is taken as statistical significant at $95 \%$ confidence interval

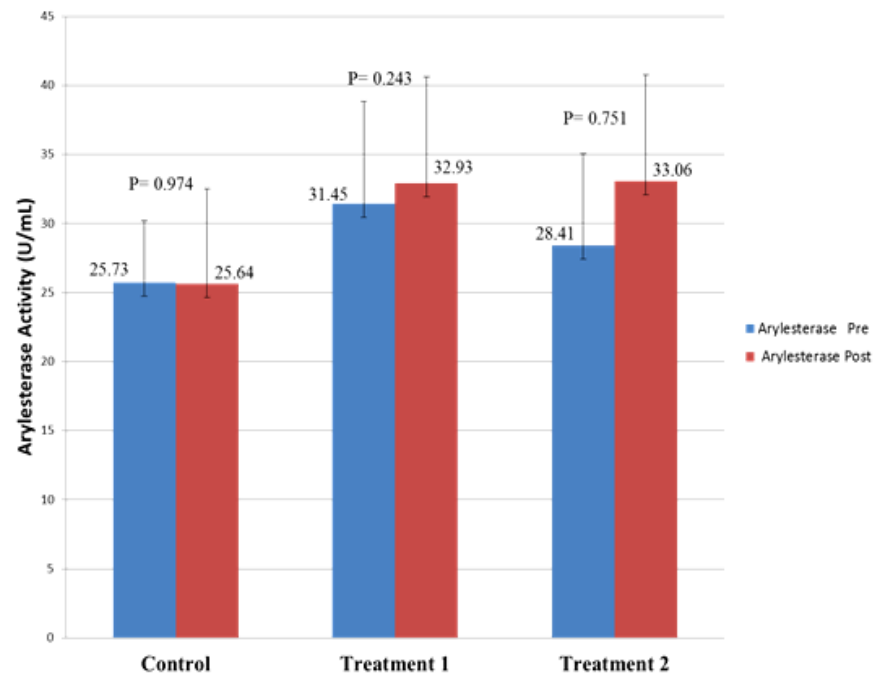

Fig. 3: Comparison of Serum Arylesterase Activity Between Pre and Post MSMA treatment. Results presented as mean (SD). Paired t-test. $\mathrm{P}<0.05$ was taken as statistically significant at $95 \%$ confidence interval. 
Table 1: Mean Organ Weight in Control and MSMA Treated Groups.

\begin{tabular}{|c|c|c|c|c|}
\hline \multirow[b]{2}{*}{ Weight (grams) } & \multicolumn{4}{|c|}{ Mean Organ Weight (grams) } \\
\hline & $\begin{array}{c}\text { Control } \\
n=8\end{array}$ & $\begin{array}{c}\text { Treatment } 1 \\
n=8\end{array}$ & $\begin{array}{c}\text { Treatment } 2 \\
n=8\end{array}$ & P-value \\
\hline Liver & $11.34(1.56)$ & $10.53(1.41)$ & $11.16(2.12)$ & 0.639 \\
\hline Kidney & $2.92(0.32)$ & $2.68(0.22)^{\mathrm{b}}$ & $2.93(0.55)$ & 0.340 \\
\hline Heart & $1.52(0.24)$ & $1.26(0.19)^{\mathrm{a}}$ & $1.39(0.32)^{\mathrm{b}}$ & 0.163 \\
\hline
\end{tabular}

Values represent mean (SD). ${ }^{a}=17 \%,{ }^{b}=8 \%$ organ weight reduction compared with control group. P<0.05 was taken to be statistically significant at $95 \%$ CI.

Table 2: Mean Relative Organ Weight in Control and MSMA Treated Groups.

\begin{tabular}{|c|c|c|c|c|}
\hline \multirow[b]{2}{*}{ Organ } & \multicolumn{4}{|c|}{ Mean Relative Organ Weight } \\
\hline & $\begin{array}{c}\text { Control } \\
n=8\end{array}$ & $\begin{array}{c}\text { Treatment } 1 \\
n=8\end{array}$ & $\begin{array}{c}\text { Treatment } 2 \\
n=8\end{array}$ & P-Value \\
\hline Liver & $0.023(0.009)$ & $0.024(0.003)$ & $0.024(0.004)$ & 0.379 \\
\hline Kidney & $0.006(0.001)$ & $0.006(0.000)$ & $0.006(0.001)$ & 0.379 \\
\hline Heart & $0.003(0.001)$ & $0.003(0.001)$ & $0.003(0.001)$ & 0.379 \\
\hline
\end{tabular}

Values represent median $(\mathrm{IQR})$. Kruskal-Walis test. $\mathrm{P}<0.05$ was taken as statistically significant at $95 \%$ confidence interval. $\mathrm{IQR}=\mathrm{Interquartile} \mathrm{range.}$

Table 3: Paraoxonase 1 (PON1) Activity in Control and MSMA treated groups.

\begin{tabular}{|c|c|c|c|c|c|}
\hline Test Parameter & $\begin{array}{c}\text { Treatment } \\
\text { Group }\end{array}$ & $\mathbf{n}$ & Mean (SD) & F-Stat (df) & P-Value \\
\hline \multirow{3}{*}{ Paraoxonase (U/ml) } & Control & 8 & $148.31(17.18)$ & \multirow{3}{*}{$8.326(2,21)$} & \multirow{3}{*}{$0.002 *$} \\
\hline & Treatment 1 & 8 & $223.54(60.45)$ & & \\
\hline & Treatment 2 & 8 & $141.81(44.72)$ & & \\
\hline \multirow{3}{*}{ Arylesterase (U/ml) } & Control & 8 & $25.64(6.888)$ & \multirow{3}{*}{$2.615(2,21)$} & \multirow{3}{*}{0.097} \\
\hline & Treatment 1 & 8 & $32.93(7.666)$ & & \\
\hline & Treatment 2 & 8 & $33.06(7.696)$ & & \\
\hline
\end{tabular}

Results presented as mean (standard deviation, SD). One way ANOVA and Tukey post hoc test.P<0.05 was taken as statistically significant at $95 \%$ confidence interval. *Significant difference $(\mathrm{p}<0.05)$ in mean paraoxonase activity between Control and Treatment group 1 with mean difference of $75.51 \mathrm{U} / \mathrm{ml}(\mathrm{CI}$ : 37.06 111.41) and between Treatment group 1 and Treatment group 2 with mean difference of 81.73U/ml (CI: 68.57 - 94.89). No significant difference in mean arylesterase activity between Control and MSMA treated groups ( $\mathrm{p}>0.05)$.

Table 4: Lipid Peroxidation Parameters in the Control and MSMA treated groups.

\begin{tabular}{|c|c|c|c|c|c|}
\hline Test Parameter & $\begin{array}{c}\text { Control Mean (SD) } \\
n=8\end{array}$ & $\begin{array}{c}\text { Treatment } 1 \text { Mean (SD) } \\
n=8\end{array}$ & $\begin{array}{c}\text { Treatment } 2 \text { Mean (SD) } \\
n=8\end{array}$ & $\begin{array}{c}\text { F-Stat } \\
\text { (df) }\end{array}$ & P-Value \\
\hline MDA (nmol/ml) & $4.70(0.93)$ & $6.75(2.64)$ & $5.96(0.87)$ & $2.93(7)$ & 0.1010 \\
\hline Ox-LDL (pmol/ml) & $199.79(37.66)$ & $1890.06(18.71)$ & $1222.03(95.94)$ & $17.05(7)$ & $<0.0001^{*}$ \\
\hline
\end{tabular}

Results presented as mean (SD). One way ANOVA and Tukey post hoc test. $\mathrm{P}<0.05$ was taken as statistically significant at $95 \%$ confidence interval.

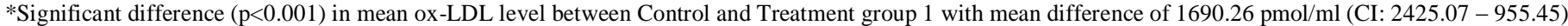
and between Control and Treatment group 2 with mean difference of 1022.23 pmol/ml (CI: $1757.04-287.42$ ).

Ox-LDL= oxidized low density lipoprotein, $\mathrm{df}=$ degree of freedom.

\section{Lipid Peroxidation Assays: Malondialdehyde (MDA) concentration and ox-LDL Level}

Table 4 presents mean (SD) of MDA concentration and ox-LDL level in Control and MSMA treated groups after 16 weeks treatment. The mean MDA concentrations were $43.60 \%$ and $26.73 \%$ higher in $\mathrm{T} 1$ and $\mathrm{T} 2$ respectively as compared to that of Control (Table 4) although there was no significant statistical difference $(\mathrm{p}>0.05)$.

Ox-LDL level in T1 was more than 8 times that of Control group while ox-LDL level in T2 was more than 5 times that of control group content. There was a significant difference $(\mathrm{p}<0.001)$ in ox-LDL level between Control and MSMA treated groups (Table 4). Comparing pre and post MSMA treatment in each group, although insignificant $(\mathrm{p}>0.05)$, Control and T1 recorded a decrease in mean MDA concentration of $4.374 \%$ and $0.604 \%$ respectively.

On the other hand, a significant increase in MDA concentration of $42.49 \%$ was recorded in Treatment group 2 . Figure 4 shows the details. The levels of ox-LDL in T1 and T2 groups were significantly increased $(p<0.0001)$ by more than 4 times and 3 times respectively after MSMA treatment as compared to before treatment. Figure 5 presents this pairwise comparison. 


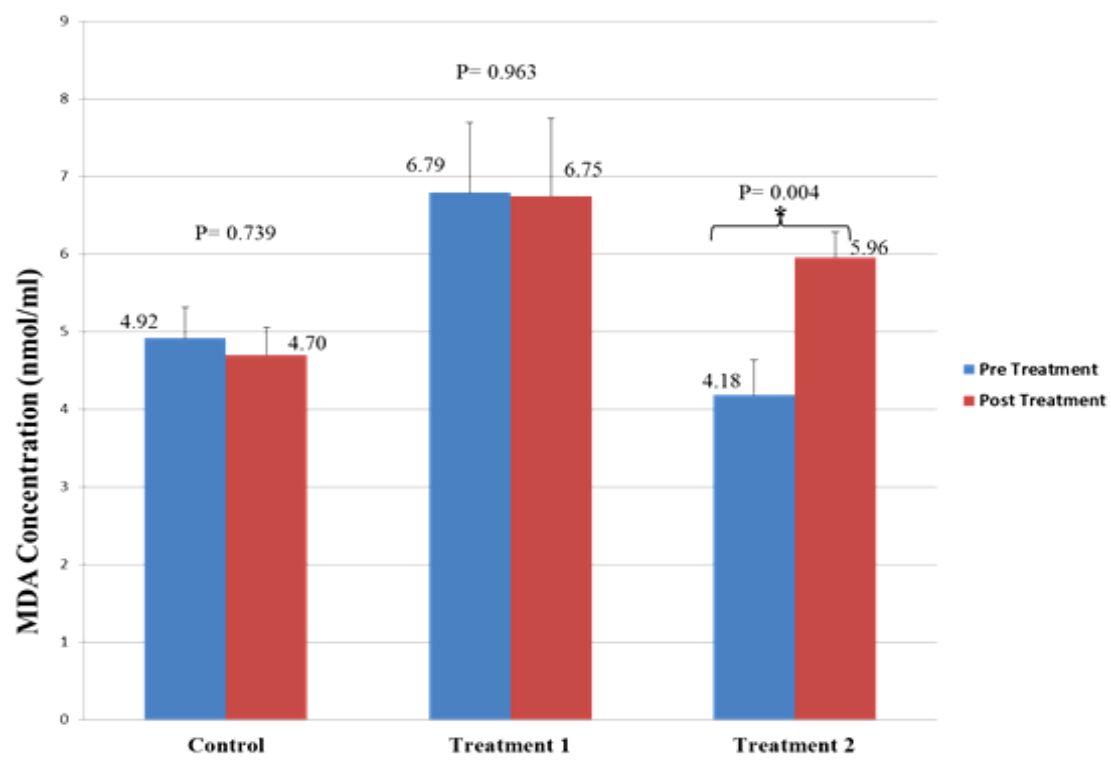

Fig. 4: Comparison of MDA Concentration Between Pre and Post MSMA Treatments. Data presented as mean (SD). Paired t-test. P $<0.05$ was taken as statistical significant at $95 \%$ confidence interval. *Significant difference in MDA concentration between pre and post MSMA treatment in Treatment group 1 with mean difference of $1.78 \mathrm{nmol} / \mathrm{ml}(\mathrm{CI}: 2.73-0.82)$.

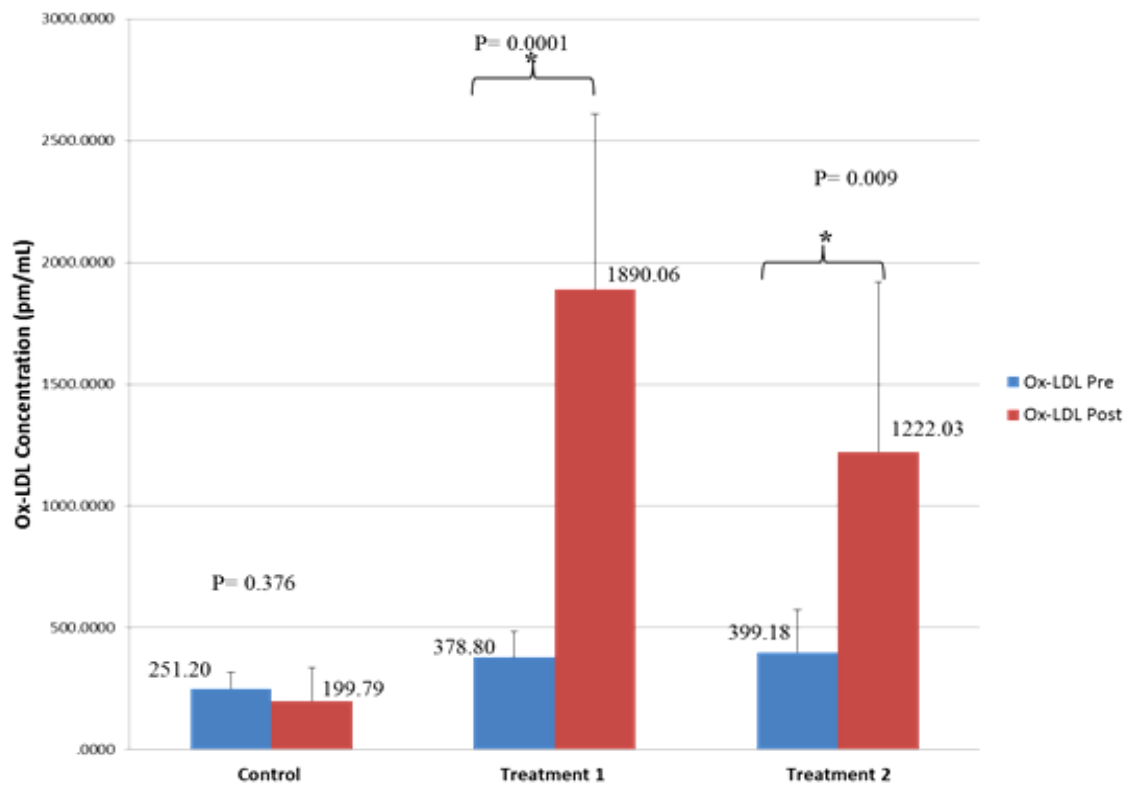

Fig. 5: Comparison of Serum Ox-LDL Level During Pre and Post MSMA Treatment. Data presented mean (SD). Paired t-test. P $<0.05$ was taken as statistically significant at $95 \%$ confidence interval. * Significant difference $(\mathrm{p}<0.05)$ between pre and post ox-LDL level in Treatment group 1 with mean difference of 1511.25 (CI: 2064.93 to 957.56 ) and in Treatment group 2 with mean difference of 822.843 (CI: 1366.68 to 279.01 ). Ox-LDL= oxidized low density lipoprotein.

\section{PON1 activities: Ox-LDL Ratios}

In order to investigate the effectiveness of PON1 ability to hydrolyse Ox-LDL in all the research groups, paraoxonase:OxLDL and arylesterase:Ox-LDL ratios were calculated for all the groups. After 16 weeks treatment, paraoxonase:ox-LDL was significantly reduced $(\mathrm{p}<0.0001)$ in both MSMA treated groups 1 and 2 as compared to that of Control group. MSMA Treatment groups 1 and 2 had $84.54 \%$ and $81.90 \%$ reduction in PON1 effectiveness in hydrolyzing ox-LDL respectively as compared to that of Control group (Table 5). Likewise, arylesterase:oxLDL were also significantly lower $(\mathrm{p}<0.0001)$ in both MSMA treated groups 1 and 2 as compared to that of Control group. MSMA treatment groups 1 and 2 had $87.07 \%$ and $77.03 \%$ reduction in
PON1 effectiveness in hydrolyzing ox-LDL respectively as compared to that of Control group (Table 5). Comparing the pre and post paraoxonase:ox-LDL and arylesterase:ox-LDL ratios, MSMA treatment groups 1 and 2 have significant differences $(\mathrm{p}<0.05)$ in their readings.

There were decrease in paraoxonase:ox-LDL ratio from pre to post Treatment in MSMA Treatment groups 1 and 2 by $77.06 \%$ and $62.00 \%$ respectively. Conversely, control group reading increased by $61.82 \%$. Arylesterase:ox-LDL in both treatments 1 and 2 were significantly decreased $(\mathrm{p}<0.05)$ by $76.45 \%$ and $54.18 \%$ respectively (Figure 6 and 7 ). In contrast, control group increased by $44.61 \%$ and was not significant $(\mathrm{p}>0.05)$. 
Table 5: Paraoxonase:Ox-LDL and Arylesterase:Ox-LDL Ratios in Control and MSMA Treated Groups After 16 Weeks of Treatment.

\begin{tabular}{cccccc}
\hline Test & Control Mean (SD) & Treatment 1 Mean (SD) & Treatment 2 Mean (SD) & \\
Parameter & $\mathbf{n = 8}$ & $\mathbf{n = 8}$ & $\mathbf{n = 8}$ & F-stat (df) & P-Value \\
\hline Paraoxonase:OxLDLRatio & $0.93(0.39)$ & $0.14(0.09)$ & $0.17(0.13)$ & $27.408(7)$ & $<0.0001^{* *}$ \\
Arylesterase:OxLDL Ratio & $0.16(0.08)$ & $0.02(0.01)$ & $0.03(0.02)$ & $22.685(7)$ & $<0.0001^{* *}$ \\
\hline
\end{tabular}

Results Presented as Mean (SD). One way ANOVA. P<0.05 was taken as statistically significant at $95 \%$ confidence interval. ** Significant difference ( $<<0.0001)$ in paraoxonase: ox-LDL ratio between Control and Treatment group 1 with mean difference of 0.79 (CI: $0.49-1.10)$ and between Control and Treatment group 2 with mean difference of 0.77 (CI: $0.46-1.07)$. Likewise, *significant difference $(\mathrm{p}<0.0001)$ in arylesterase:ox-LDL ratio between Control and Ttreatment group 1 with mean difference of 0.14 (CI: $0.08-0.20$ ) and between control and treatment 2 group with mean difference of 0.13 (CI: $0.07-0.18)$. Paraoxonase:Ox-LDL $=$ paraoxonaseto oxidised low density lipoprotein ratio. Arylesterase:Ox-LDL= arylesterase to oxidised low density lipoprotein ratio.

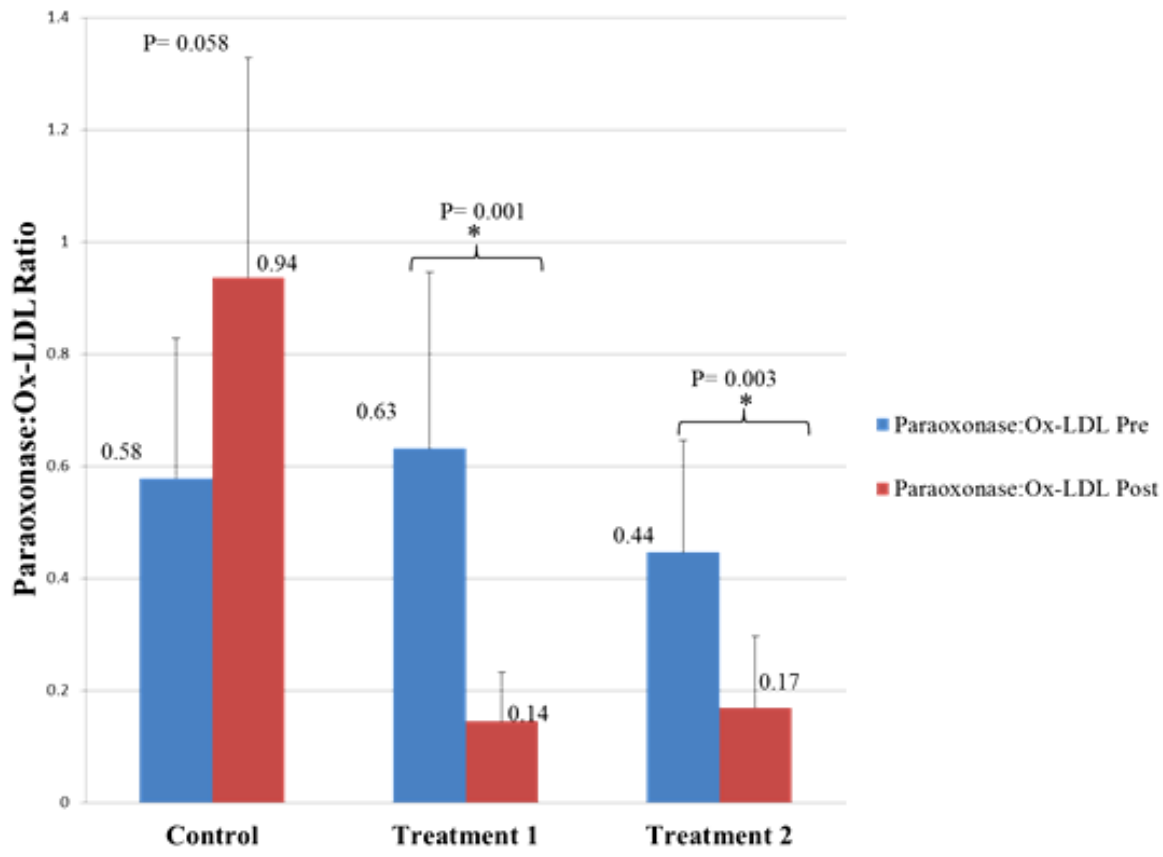

Fig. 6: Comparison of Paraoxonase:OxLDL During Pre and Post MSMA Treatment. Data presented as are mean (SD). Paired t-test. P $<0.05$ was taken as statistically significant at $95 \%$ confidence interval. *significant difference $(\mathrm{p}<0.05)$ in paraoxonase: Ox-LDL ratio between pre and post MSMA treatment in Treatment group 1 with mean difference of 0.49 (CI: $0.28-0.70$ ) and in Treatment group 2 with mean difference of 0.28 (CI: 0.13 - 0.43 ). Paraoxonase: Ox-LDL = paraoxonase oxidized low density lipoprotein ratio.

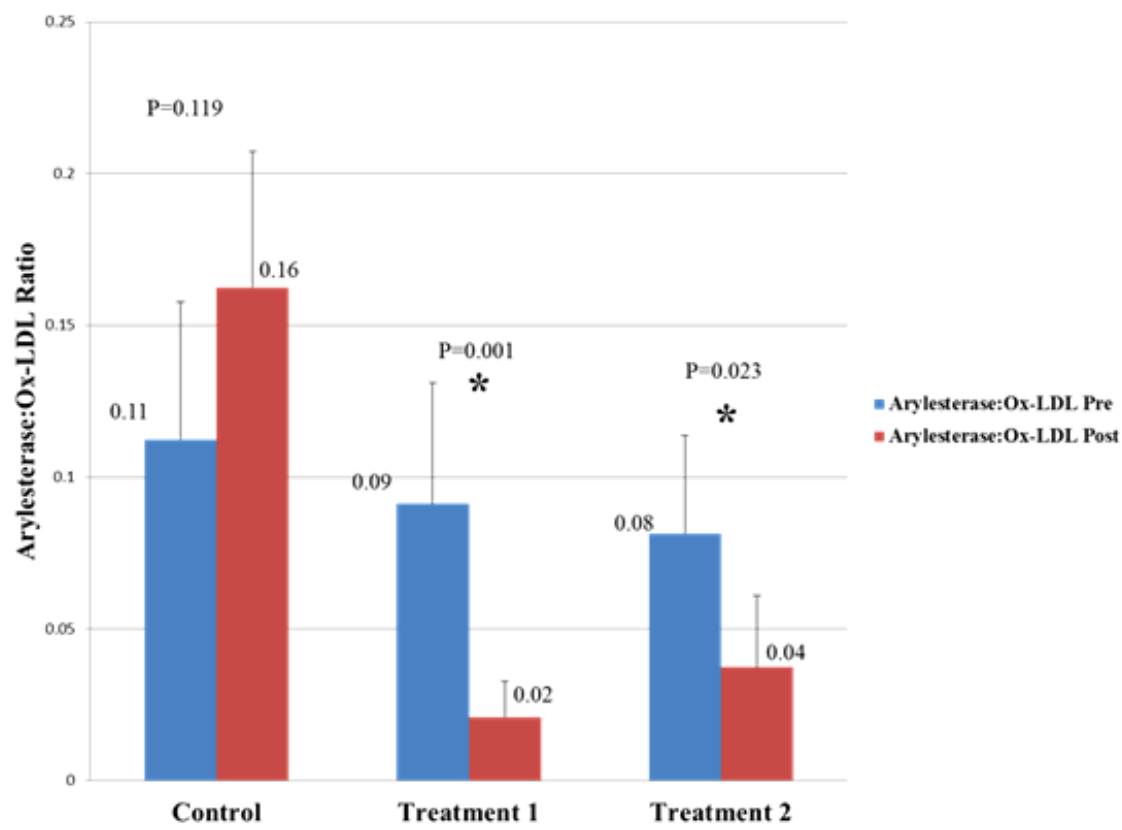

Fig. 7: Comparison of Arylesterase: OxLDL During Pre and Post MSMA Treatment. Data presented as are mean (SD). Paired t-test. P $<0.05$ was taken as statistically significant at $95 \%$ confidence interval. *significant difference $(\mathrm{p}<0.05)$ in Arylesterase:Ox-LDL ratio between pre and post MSMA treatment in Treatment group 1 with mean difference of 0.07 (CI: $0.04-0.10)$ and in Treatment group 2 with mean difference of 0.04 (CI: $0.01-0.08$ ). Arylesterase:Ox-LDL $=$ Arylesterase oxidized low density lipoprotein ratio. 


\section{Histomorphometric Assessments of Aorta}

The histological examination of the aorta sections stained by $\mathrm{H} \& \mathrm{E}$ showed early atherosclerosis changes observed in MSMA treated groups (Figure 8). There were some areas that showed intracellular lipid deposition between the internal elastic lamina (IEL) and endothelial layer indicating a thickened tunica intima. The endothelial cells seem sparse and distorted as compared to regular lining in Control group (Figure 8). Special staining of the aorta's elastic fibre with VVG stain precisely showed the position of the IEL in relation to the endothelium thus delineate better the tunica intima and the tunica media (Figure 9). More precisely, Immunohistochemistry (IHC) of the aorta showed positive adhesion molecules VCAM-1and ICAM-1 (Figure 10) expression in aorta of both Treatment 1 and 2 groups (Figure 11).
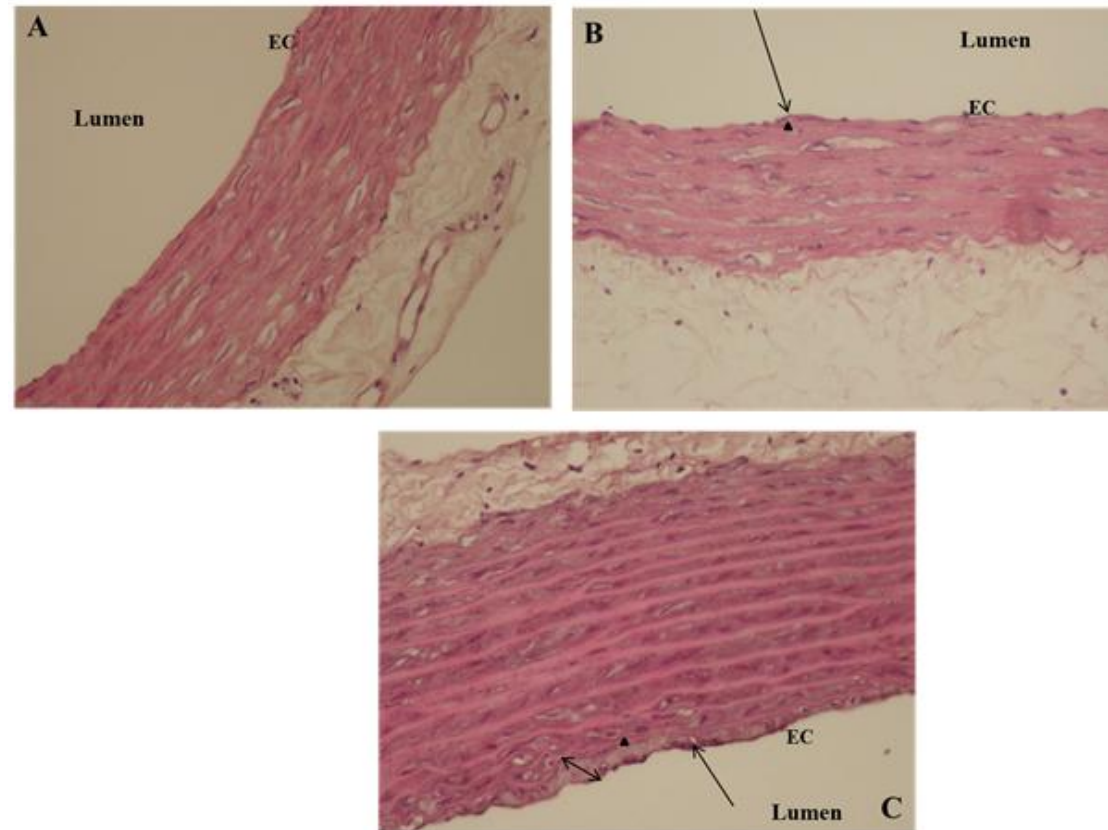

Fig. 8: Microscopic View of Aorta Stained with H\&E in Control and MSMA treated groups at $x 40$ magnification. A: Control, B: Treatment 1, C: Treatment 2. Arrows point to the areas of endothelial malformation in MSMA treated groups (B and C). Black triangle shows the position of the internal elastic lamina (IEL) and EC is the endothelial cell. Black double head arrow shows the distance between the endothelium and the IEL, indicative of thickened intima (C) due to the presence of early deposition of fatty deposits in the tunica intima (B and C).
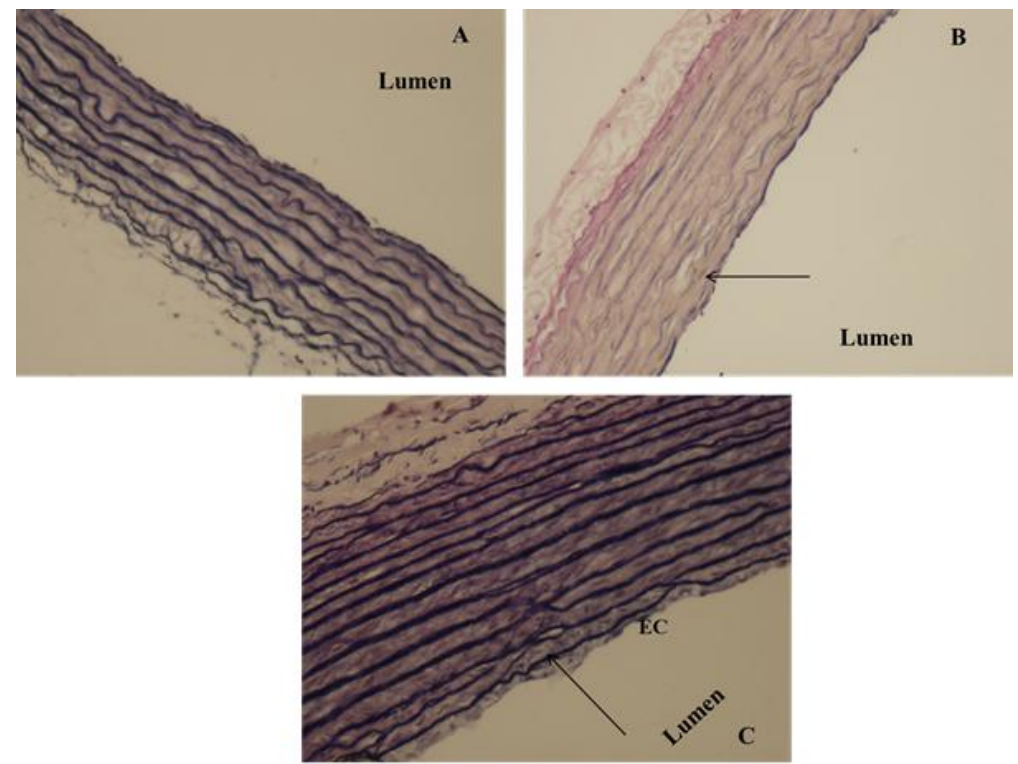

Fig. 9: Microscopic View of Aorta Stained with VVG in Control and MSMA treated groups. A: Control, B: Treatment 1, C: Treatment 2. Black arrow shows displaced IEL as a result of thickened tunica intima (black arrow) in B and C (x40). 

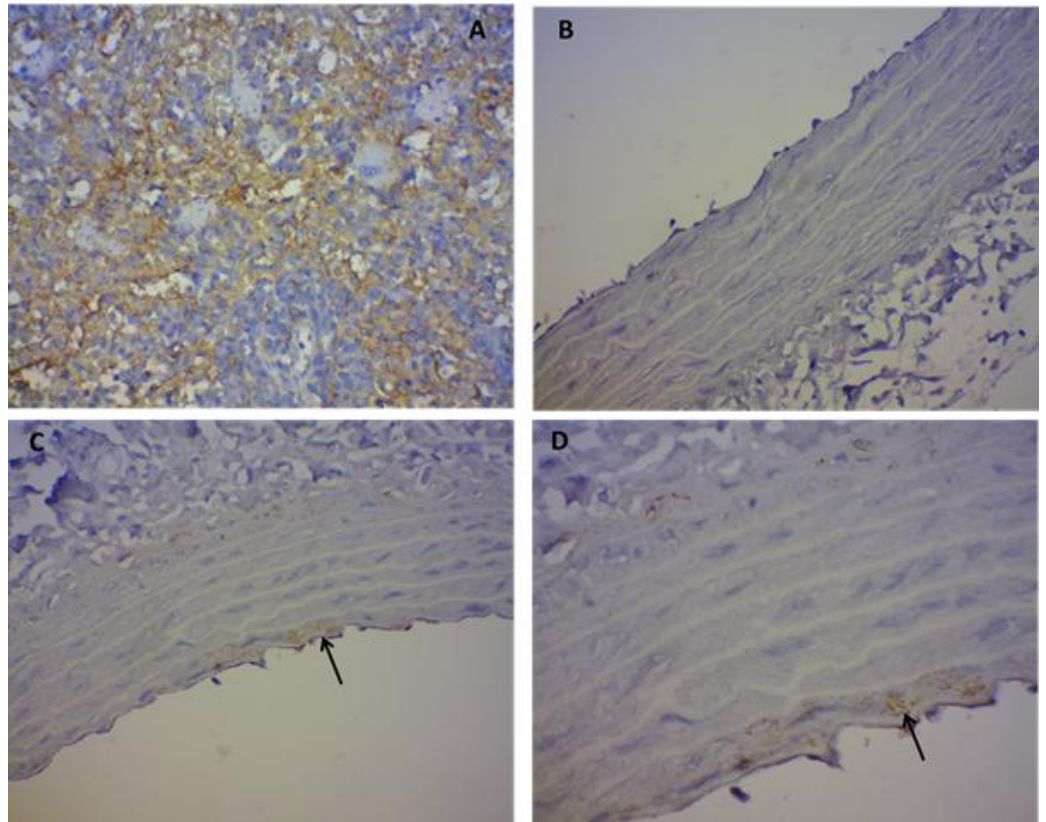

Fig. 10: Microscopic View of Aorta Stained with IHC VCAM-1 in Control and MSMA Treated Groups (x40 magnification). A: Positive control (rat spleen), B: Control group, C: Treatment 1 group, D: Treatment 2 group. Positive VCAM-1 expression in C and D (black arrow).
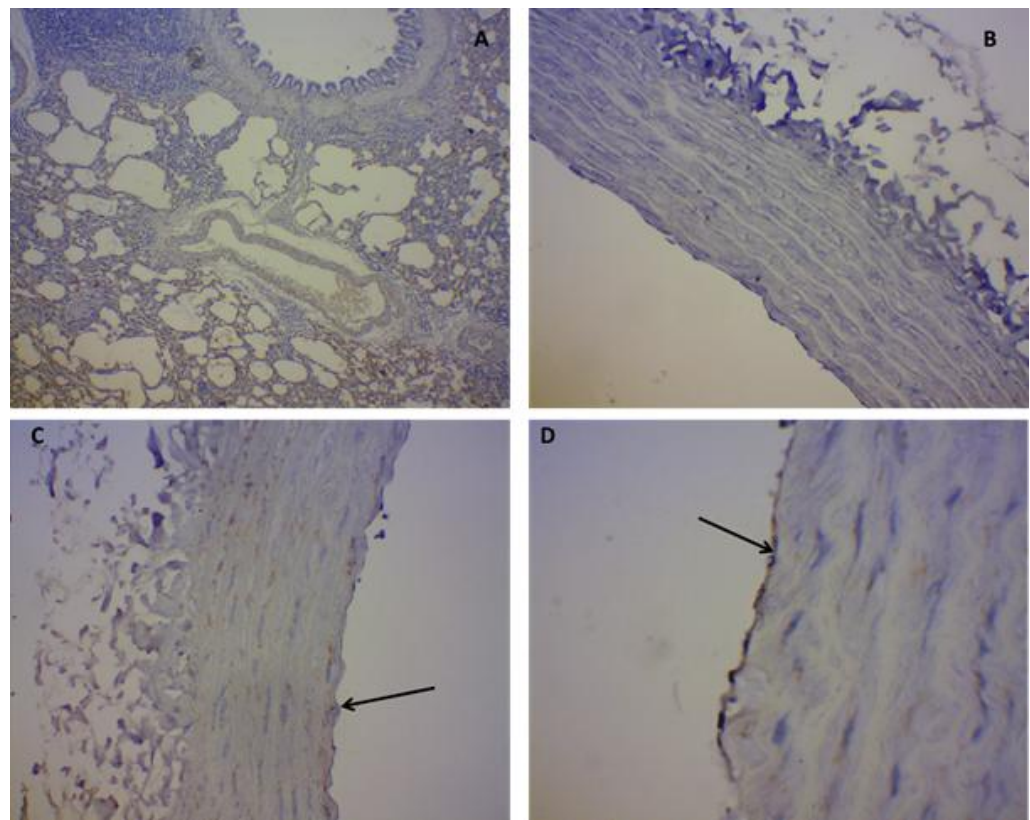

Fig. 11: Microscopic View of Aorta Stained with IHC ICAM-1 in Control and MSMA treated groups (x40 magnification). A: Positive control (rat lung), B: Control group, C: Treatment 1 group, D: Treatment 2 group. Positive ICAM-1 expression in C and D (black arrow).

\section{DISCUSSION}

Toxic effect of MSMA on body and organ weight of experimental subjects has been reported in a few studies (Arnold $e t$ al., 2003, Albert et al., 2007) involving different animals. For example, acute exposure to low and high doses $(8,24,72 \mu \mathrm{g} / \mathrm{g}$ body weight) of $\mathrm{MMA}^{(\mathrm{V})}$ was detected to significantly retard the growth and body weight of nestling Zebra Finches (Albert et al., 2008). Our result is in agreement with a previous study on low dose $\left(4 \mu \mathrm{g} / \mathrm{g}\right.$ body weight) of MMA ${ }^{(\mathrm{v})}$ which also reported nonsignificant weight decrease in their 2 weeks study (Arnold $e t$ al., 2003). Slight weight reduction in MSMA exposed group could be due to stimulation of diarrhea as a result of MSMA ingestion (Arnold et al., 2003). 
Several investigations have identified the role of PON1 in cardiovascular diseases (Eckerson et al., 1983, Aviram et al., 1998, Durrington et al., 2001, Mackness et al., 2001, Li et al., 2009, Mackness and Mackness, 2015). Human experimental study carried out on carotid atherosclerotic patients of arsenic endemic area in Taiwan showed that increased arsenic exposure in $\mathrm{mg} / \mathrm{L}$ year correlates with low PON1 activity (Li et al., 2009). Apart from arsenic, various other metals such as lead $(\mathrm{Pb})$, cadmium $(\mathrm{Cd})$, Zinc ( $\mathrm{Zn})$, selenium (Se), mercury ( $\mathrm{Hg}$ ) and manganese (Mn) have also been discovered to also modulate PON1 activities (Hernández et al., 2009, Ekinci and Beydemir, 2010, Ginsberg et al., 2014, Laird et al., 2015). Modulatory effects of these heavy metals were attributed to the binding of these metals to the free sulfydryl group on cysteine amino acid at position 283 of PON1 active site (Aviram et al., 1998; Costa et al., 2005; Afolabi et al., 2014). Experimental studies investigating organic arsenic exposure effect on PON1 activities and antioxidant property are very limited. Reduced PON1 paraoxonase and arylesterase activities were reported in oral inorganic arsenic (sodium arsenite) exposed rats (Afolabi et al., 2013; Afolabi et al., 2014). However, in the present study, PON1 activities were not significantly different before and after oral MSMA exposure.

MDA is the peroxidative product of polyunsaturated fatty acids (PUFA) attacked by ROS and is used as a biomarker for oxidative stress (Mateos et al., 2005). Oxidative stress has been implicated in the pathology of many diseases including inflammation, cancer, cellular aging, atherosclerosis and genotoxicity (Mateos et al., 2005; Bhadauria and Flora, 2007). Arsenic toxicity has been postulated to occur through ROS generated oxidative stress deteriorated PUFAs (Bhadauria and Flora, 2007). This is supported by studies which discovered that iAs induces lipid peroxidation in a dose dependent manner in experimental animals (Odunola et al., 2013). Likewise, epidemiological evidence of the cardiovascular toxicity of inorganic arsenic is also mounting. Arsenic toxicity has been identified to correlate with increased incidence of atherosclerotic cardiovascular diseases in Taiwan, Bangladesh and West Bengal, India (Chen et al., 1996; Rabbani and Saha, 2000; Chen et al., 2007; Chen et al., 2009). In this current study, although insignificant, the MDA concentrations were found to be higher among MSMA exposed groups as compared to that of control group. Further, when compared between pre and post MSMA exposure, T2 group was found to have a significantly higher ( $p<0.05)$ MDA concentration after MSMA exposure. The present results agrees with previous animal experimental study investigating 12 months oral exposure to arsenic-containing well water which also discovered significant serum MDA increase in the exposed group (Santra et al., 2000). Another study by Kaur et al. (2010) also reported a significant elevation in serum MDA in sodium arsenite exposed group as compared to that of control group (Kaur et al., 2010). Likewise, arsenic trioxide also invoked significant increase in blood TBARS level after treatment for a week (Rabbani et al., 2003). Conversely, a two days sodium arsenite (iAs) exposure animal study failed to discover any significant increase in rat's liver MDA content (Schinella et al., 1996). This disparity might be attributed to the very short exposure period and difference in samples assessed. Our result showed that organic arsenicals, MSMA, used as potent active ingredient of herbicides is capable of generating oxidative stress and lipid peroxidation in vivo similar to its inorganic counterpart. Hence, possessing potentials to contribute towards pathology of oxidative stress induced diseases such as atherosclerosis.

Ox-LDL also contributes immensely toward endothelial injury that initiates atherosclerosis which leads to CVD (Steinberg, 1997, Steinberg and Witztum, 2010, Shah, 2013). Meanwhile, atherosclerosis and other CVD have been reported to be prevalent in arsenic contamination endemic regions of Taiwan and India (Tseng, 2008; Srivastava et al., 2009). In this present study, a significant increase $(\mathrm{p}<0.0001)$ were noted in serum ox-LDL levels in MSMA treated groups 1 and 2 as compared to that of control group (Table 6). The present result agrees with previous human experimental study which also reported higher plasma oxLDL in Bangladeshi arsenic exposed people (Karim et al., 2013). In the meantime, another study reported a significantly increased plasma ox-LDL in CAD patients (Holvoet et al., 1998). Thus, current study draws our attention to the LDL oxidation capacity of MSMA and its imminent endothelial injury which can induce atherosclerosis and CAD.

PON1 ability to hydrolyse ox-LDL was assessed by calculating paraoxonase:oxLDL and arylesterase:ox-LDL ratios. In the present study, the paraoxonase:ox-LDL and arylesterase:oxLDL ratios were found to be significantly lower $(\mathrm{p}<0.0001)$ in MSMA treated groups as compared to that of Control group. Similarly, when the paraoxonase:ox-LDL and arylesterase:ox-LDL ratios were compared between pre and post MSMA exposure, both Treatment groups 1 and 2 were found to have a significantly reduced $(\mathrm{p}<0.0001)$ PON1 ability to hydrolyse ox-LDL. Our results corroborate previous studies' postulation that PON1 activities and prevention of LDL oxidation are mutually exclusive (Aviram et al., 1998; Durrington et al., 2001; Li et al., 2009; Efrat and Aviram, 2010). Previous study reported that arsenic binds to free cysteine 283 free sulfydryl group on PON1 and this sulfydryl group is needed for successful prevention of LDL oxidation by PON1 (Aviram et al., 1998). Current study's findings suggested that PON1 cysteine 283 free sulfydryl group might be affected by MSMA exposure since paraoxonase:ox-LDL and arylesterase:oxLDL ratios were lower in MSMA treatment groups as compared to control. Therefore, our study showed that PON1 antioxidant ability was also significantly reduced with MSMA exposure. Hence, MSMA exposure will encourage atherosclerosis-induced CVD development.

The histopathologic role of inflammation in atherosclerosis induced CAD had been established over the decades (Paeng, 2013; Shah, 2013). In the current study, H\&E stained aortas of Control and MSMA treated rats showed early deposition of atherogenic plaques in the tunica intima in both Treatment group 1 and 2 administered with 42.1 and $63.2 \mathrm{mg} / \mathrm{kg}$ body weight MSMA (Figure 11B and C) while aorta of rats in 
control group showed a perfectly normal and consistent endothelium (Figure 11A). Present study's result also affirms previous study's view of inflammatory potential of MSMA toxicity (Jaghabir et al., 1989). Similarly, more recent study reported that oral exposure to arsenic trioxide induced plaque deposition in aorta of rats (Cheng et al., 2011). In order to provide a better assessment, Verhoeff Van Geison staining was used to stain the aorta elastic fibres as black and collagen as pink. Present study's result shows that the IEL of aorta in MSMA treated groups were displaced by atheromatus plague deposit from the endothelium (Figure 12). This indicates that there is thickening of the tunica intima of the MSMA treated groups which is an evidence of early atherosclerotic development. Current result is synonymous to that of a previous study which also reported displaced IEL in human early degenerative aortic stenosis: a condition that shared active inflammatory process with atherosclerosis (Otto et al., 1994).

Pathologically, the onset of atherosclerosis is marked by transmigration of inflammation-stimulated leukocytes across the endothelium into the vessel wall. It requires the recruitment of various adhesion molecules such as vascular adhesion molecule (VCAM-1), intracellular adhesion molecule (ICAM-1), P-selectins and E-selectins (Roy et al., 2009). In arsenic pollution endemic areas, epidemiological studies have found a significant relationship between plasma soluble vascular adhesion molecule (sVCAM-1) and soluble intracellular adhesion molecule (sICAM-1) (Chen et al., 2007). Immunohistochemical analysis of atherosclerotic hypercholesterolemic rabbit's aorta showed considerable expression of both ICAM-1 and VCAM-1 (Koga et al., 2004). Epidemiologic studies have established the involvement of ICAM1 and VCAM-1 in arsenic pollution-induced CVD. Current study found out that organic arsenic, MSMA, exposed rats aorta showed positive VCAM-1 and ICAM-1 expression (Figure 13 and 14).

Our results agree with previous study which reported increased expression of ICAM-1 and VCAM-1 in aorta of atherosclerotic hypercholesterolemic rabbits using IHC as well (Koga et al., 2004). It also conforms with epidemiological results previously reported (Chen et al., 2007; Karim et al., 2013). Therefore, our study is presenting for the first time that organic arsenic (MSMA) exposure is atherogenic and can contribute to the burden of CVD experienced worldwide.

\section{CONCLUSION}

In conclusion, this study showed that chronic MSMA exposure is capable of lowering PON1 antioxidant ability to hydrolyse ox-LDL. To the same effect, lipid peroxidation level, as measured by serum MDA and ox-LDL contents, is exacerbated by chronic MSMA exposure. It also initiates early histomorphological alteration of the aorta towards atherosclerotic changes and positively expressed inflammatory markers of VCAM-1 and ICAM-1. Therefore, these point to the fact that chronic MSMA exposure induces early atherosclerosis changes in rats, which could be explained by elevated oxidative stress, inflammation and reduced ability of PON1 to hydrolyse oxidised LDL.

\section{ACKNOWLEDGEMENT}

Authors would like to thank medical laboratory Technologists of Biochemistry and Histopathology, Department of Basic Medical Sciences, Kulliyyah of Medicine, IIUM for their technical support. Likewise, we will also like to thank authorities and staffs of Natural Product Laboratory and Pharmaceutical Science Research Laboratory, Kulliyyah of Science and Kulliyyah of Pharmacy, IIUM respectively for granting us the permission to use some of their equipment.

Financial support and sponsorship: This study was supported by the Fundamental Research Grant Scheme (FRGS 14-110-0351) awarded to Nor Zamzila Abdullah (M.D, M.Path).

Conflict of Interests: There are no conflicts of interest.

\section{REFERENCES}

Afolabi O, Oyewo E, Adekunle A, Adedosu O, Adedeji A.Assessment Of Lipid Peroxidation Markers And Roinflammatory Cytokines In Arsenite-Exposed Rats. Assessment, 2013; 2:8-18.

Afolabi OK, Wusu AD, Ogunrinola OO, Abam EO, Babayemi DO, Dosumu OA, Onunkwor OB, Balogun EA, Odukoya OO, Ademuyiwa O. Paraoxonase 1 activity in subchronic low-level inorganic arsenic exposure through drinking water. Environmental toxicology, 2014; 001-019.

Albert C, Williams TD, Morrissey CA, Lai VW, Cullen WR, Elliott JE. Tissue uptake, mortality, and sublethal effects of monomethylarsonic acid (MMA(V)) in nestling zebra finches (Taeniopygia guttata). Journal of toxicology and environmental health Part A, 2008; 71:353-360.

Albert CA, Williams TD, Morrissey CA, WM-Lai V, Cullen WR, Elliott JE. Dose-dependent uptake, elimination, and toxicity of monosodium methanearsonate in adult zebra finches (Taeniopygia guttata). Environmental Toxicology and Chemistry, 2007; 27:605-611.

Ancom. MSMA 720 Material Safety Data Sheet. 2012; 7: https://www.dropbox.com/s/diiyehz5qm1uju3/MSMA720.pdf?dl=0.

Arnold LL, Eldan M, van Gemert M, Capen CC, Cohen SM. Chronic studies evaluating the carcinogenicity of monomethylarsonic acid in rats and mice. Toxicology, 2003; 190:197-219.

Aviram M, Billecke S, Sorenson R, Bisgaier C, Newton R, Rosenblat M, Erogul J, Hsu C, Dunlop C, La Du B. Paraoxonase Active Site Required for Protection Against LDL Oxidation Involves Its Free Sulfhydryl Group and Is Different From That Required for Its Arylesterase/Paraoxonase Activities : Selective Action of Human Paraoxonase Allozymes Q and R. Arteriosclerosis, Thrombosis, and Vascular Biology, 1998; 18:1617-1624.

Bhadauria S, Flora S. Response of arsenic-induced oxidative stress, DNA damage, and metal imbalance to combined administration of DMSA and monoisoamyl-DMSA during chronic arsenic poisoning in rats. Cell biology and toxicology, 2007; 23:91-104.

Bolt HM. Arsenic: an ancient toxicant of continuous public health impact, from Iceman Otzi until now. Archives of toxicology, 2012; 86:825-830.

Bolt HM. Current research trends on arsenic toxicology. Archives of toxicology, 2013; 87:925-926.

Casale T, Rosati MV, Ciarrocca M, Samperi I, Andreozzi G, Schifano MP, Capozzella A, Pimpinella B, Tomei G, Caciari T, Tomei F. 
Assessment of liver function in two groups of outdoor workers exposed to arsenic. International archives of occupational and environmental health, 2014; 87:745-752.

Chen C-J, Chiou H-Y, Chiang M-H, Lin L-J, Tai T-Y. Doseresponse relationship between ischemic heart disease mortality and longterm arsenic exposure. Arteriosclerosis, thrombosis, and vascular biology, 1996; 16:504-510.

Chen Y, Factor-Litvak P, Howe GR, Graziano JH, Brandt-Rauf P, Parvez F, van Geen A, Ahsan H. Arsenic exposure from drinking water, dietary intakes of B vitamins and folate, and risk of high blood pressure in Bangladesh: a population-based, cross-sectional study. American journal of epidemiology, 2007; 165:541-552.

Chen Y, Parvez F, Gamble M, Islam T, Ahmed A, Argos M, Graziano JH, Ahsan H. Arsenic exposure at low-to-moderate levels and skin lesions, arsenic metabolism, neurological functions, and biomarkers for respiratory and cardiovascular diseases: review of recent findings from the Health Effects of Arsenic Longitudinal Study (HEALS) in Bangladesh. Toxicology and applied pharmacology, 2009; 239:184-192.

Chen Y, Wu F, Graziano JH, Parvez F, Liu M, Paul RR, Shaheen I, Sarwar G, Ahmed A, Islam T, Slavkovich V, Rundek T, Demmer RT, Desvarieux M, Ahsan H. Arsenic exposure from drinking water, arsenic methylation capacity, and carotid intima-media thickness in Bangladesh. American journal of epidemiology, 2013; 178:372-381.

Cheng TJ, Chuu JJ, Chang CY, Tsai WC, Chen KJ, Guo HR. Atherosclerosis induced by arsenic in drinking water in rats through altering lipid metabolism. Toxicology and applied pharmacology, 2011; 256:146-153

Costa LG, Vitalone A, Cole TB, Furlong CE. Modulation of paraoxonase (PON1) activity. Biochemical pharmacology, 2005; 69:541550 .

De Capitani EM, Vieira RJ, Madureira PR, Mello SM, Kira CS, Soubhia PC, Toledo AS. Auditory Neurotoxicity and Hepatotoxicity After MSMA (Monosodium Methanarsenate) High Dose Oral Intake. Clinical toxicology, 2005; 43:287-289.

Durrington PN, Mackness B, Mackness MI. Paraoxonase and Atherosclerosis. Arteriosclerosis, Thrombosis, and Vascular Biology, 2001; 21:473-480.

Eckerson HW, Romson J, Wyte C, La Du B. The human serum paraoxonase polymorphism: identification of phenotypes by their response to salts. American journal of human genetics, 1983; 35:214.

Efrat M, Aviram M. Paraoxonase 1 interactions with HDL, antioxidants and macrophages regulate atherogenesis - a protective role for HDL phospholipids. Advances in experimental medicine and biology, 2010; 660:153-166.

Ekinci D, Beydemir Ş. Purification of PON1 from human serum and assessment of enzyme kinetics against metal toxicity. Biological trace element research, 2010; 135:112-120.

Gan KN, Smolen A, Eckerson HW, La Du BN. Purification of human serum paraoxonase/arylesterase. Evidence for one esterase catalyzing both activities. Drug Metabolism and Disposition, 1991; 19:100-106.

Garelick H, Jones H, Dybowska A, Valsami-Jones E. Arsenic pollution sources: Springer, 2008.

Ginsberg G, Sonawane B, Nath R, Lewandowski P. Methylmercury-induced inhibition of paraoxonase-1 (PON1)Implications for cardiovascular risk. Journal of Toxicology and Environmental Health, Part A, 2014; 77:1004-1023.

Hammid ANA, Kuntom A, Ismail R, Pardi N. Determination of Arsenic in Palm Kernel Expeller using Microwave Digestion and Graphite Furnace Atomic Absorption Spectrometry Method. International Journl of Basicand, 2013.

Hao W, Zhu Y, Meng L, Ni C, Yang J, Zhou H. Serum paraoxonase, arylesterase activity, and oxidative status in patients with nasal polyp. European archives of oto-rhino-laryngology : official journal of the European Federation of Oto-Rhino-Laryngological Societies, 2013; 270:1861-1865.

Hernández AF, Gil F, Leno E, López O, Rodrigo L, Pla A. Interaction between human serum esterases and environmental metal compounds. Neurotoxicology, 2009; 30:628-635.
Hessl SM, Berman E. Severe peripheral neuropathy after exposure to monosodium methyl arsonate. Clinical toxicology, 1982; 19:281-287.

Holvoet P, Vanhaecke J, Janssens S, Van de Werf F, Collen D. Oxidized LDL and malondialdehyde-modified LDL in patients with acute coronary syndromes and stable coronary artery disease. Circulation, 1998; 98:1487-1494.

Hughes MF, Beck BD, Chen Y, Lewis AS, Thomas DJ. Arsenic exposure and toxicology: a historical perspective. Toxicological sciences : an official journal of the Society of Toxicology, 2011; 123:305-332.

Ilyas M, Sudaryanto A, Anantasena Y, Takahashi S, Tanabe S. Is Arsenic a Potential Threat for Human Health in Indonesia? Interdisciplinary Studies on Environmental Chemistry-Environmental Research in Asia (Eds Y Obayashi, T Isobe, A Subramanian, S Suzuki, S Tanabe) Terrapub, Tokyo, 2009.

Jaghabir M, Abdelghani A, Anderson A. Histopathological effects of monosodium methanearsonate (MSMA) on New Zealand white rabbits (Oryctalagus cuniculus). Bulletin of environmental contamination and toxicology, 1989; 42:289-293.

Karim MR, Rahman M, Islam K, Al Mamun A, Hossain S, Hossain E, Aziz A, Yeasmin F, Agarwal S, Hossain MI. Increases in oxidized low-density lipoprotein and other inflammatory and adhesion molecules with a concomitant decrease in high-density lipoprotein in the individuals exposed to arsenic in Bangladesh. toxicological sciences, $2013 ; 135: 17-25$.

Kato M, Onuma S, Kato Y, Thang ND, Yajima I, Hoque MZ, Shekhar HU. Toxic elements in well water from Malaysia. Toxicological \& Environmental Chemistry, 2010; 92:1609-1612.

Kaur T, Goel RK, Balakumar P. Effect of rosiglitazone in sodium arsenite-induced experimental vascular endothelial dysfunction. Archives of pharmacal research, 2010; 33:611-618.

Kei S. Serum lipid peroxide in cerebrovascular disorders determined by a new colorimetric method. Clinica chimica acta, 1978 90:37-43.

Koga T, Kwan P, Zubik L, Ameho C, Smith D, Meydani M. Vitamin E supplementation suppresses macrophage accumulation and endothelial cell expression of adhesion molecules in the aorta of hypercholesterolemic rabbits. Atherosclerosis, 2004; 176:265-272.

Laird BD, Goncharov AB, Ayotte P, Chan HM. Relationship between the esterase paraoxonase-1 (PON1) and metal concentrations in the whole blood of Inuit in Canada. Chemosphere, 2015; 120:479-485.

Lee M-Y, Jung B-I, Chung S-M, Bae O-N, Lee J-Y, Park J-D, Yang J-S, Lee H, Chung J-H. Arsenic-Induced Dysfunction in Relaxation of Blood Vessels. Environmental Health Perspectives, 2002; 111:513-517.

Li W-F, Sun C-W, Cheng T-J, Chang K-H, Chen C-J, Wang SL. Risk of carotid atherosclerosis is associated with low serum paraoxonase (PON1) activity among arsenic exposed residents in Southwestern Taiwan. Toxicology and applied pharmacology,2009; 236:246-253.

Mackness B, Davies GK, Turkie W, Lee E, Roberts DH, Hill E, Roberts C, Durrington PN, Mackness MI. Paraoxonase Status in Coronary Heart Disease: Are Activity and Concentration More Important Than Genotype? Arteriosclerosis, Thrombosis, and Vascular Biology, 2001; 21:1451-1457.

Mackness M, Mackness B. Human paraoxonase-1 (PON1): Gene structure and expression, promiscuous activities and multiple physiological roles. Gene, 2015.

Mateos R, Lecumberri E, Ramos S, Goya L, Bravo L. Determination of malondialdehyde (MDA) by high-performance liquid chromatography in serum and liver as a biomarker for oxidative stress: Application to a rat model for hypercholesterolemia and evaluation of the effect of diets rich in phenolic antioxidants from fruits. Journal of Chromatography B, 2005; 827:76-82.

Morrissey CA, Dods PL, Elliott JE. Pesticide treatments affect mountain pine beetle abundance and woodpecker foraging behavior. Ecological Applications, 2008; 18:172-184.

Nordstrom DK. Worldwide occurrences of arsenic in ground water. Science, 2002; 296:2143-2145. 
Odunola OA, Muhammad A, Farooq AD, Dalvandi K, Rasheed H, Choudhary MI, Erukainure OL. Comparative assessment of redoxsensitive biomarkers due to acacia honey and sodium arsenite administration in vivo. Mediterranean Journal of Nutrition and Metabolism, 2013; 6:119-126.

Ong G, Yap C, Maziah M, Suhaimi H, Tan S. An investigation of arsenic contamination in Peninsular Malaysia based on Centella asiatica and soil samples. Environmental monitoring and assessment, 2013; 185:3243-3254.

Otto CM, Kuusisto J, Reichenbach DD, Gown AM, O'Brien KD. Characterization of the early lesion of'degenerative'valvular aortic stenosis. Histological and immunohistochemical studies. Circulation, 1994; 90:844-853.

Paeng J-C. Atherosclerosis, 2013; 249-255.

Rabbani G, Saha S. Chronic arsenic toxicity through contaminated drinking water in Bangladesh: Magnitude of the problem, health effects and detoxification. The Orion, 2000; 11:3-7.

Rabbani GH, Saha SK, Akhtar M, Marni F, Mitra AK, Ahmed S, Alauddin M, Bhattacharjee M, Sultana S, Chowdhury AA. Antioxidants in detoxification of arsenic-induced oxidative injury in rabbits: preliminary results. Journal of Environmental Science and Health, Part A, 2003; 38:273-287.

Roy H, Bhardwaj S, Yla-Herttuala S. Molecular genetics of atherosclerosis. Human genetics, 2009; 125:467-491.

Samsuddin N, Rampal KG, Ismail NH, Abdullah NZ, Nasreen HE. Pesticides Exposure and Cardiovascular Hemodynamic Parameters Among Male Workers Involved in Mosquito Control in East Coast of Malaysia. American journal of hypertension, 2015; hpv093.

Santra A, Maiti A, Das S, Lahiri S, Charkaborty SK, Guha Mazumder DN, Guha Mazumder D. Hepatic damage caused by chronic arsenic toxicity in experimental animals. Clinical toxicology, 2000; 38:395-405.

Sawka MN, Cheuvront SN, Carter R. Human water needs. Nutrition reviews, 2005; 63:S30-S39.

Schinella G, Tournier H, Buschiazzo H, Buschiazzo PD. Effect of arsenic $(\mathrm{V})$ on the antioxidant defense system: in vitro oxidation of rat plasma lipoprotein. Pharmacology \& toxicology, 1996; 79:293-296.
Shah PK.Pathogenesis of Atherosclerosis, 2013; 377-386.

Srivastava S, Chen Y, Barchowsky A. Arsenic and cardiovascular disease. Toxicological sciences, 2009; 107:312-323.

Stea F, Bianchi F, Cori L, Sicari R. Cardiovascular effects of arsenic: clinical and epidemiological findings. Environmental science and pollution research international. 2014; 21:244-251.

Steinberg D. Low density lipoprotein oxidation and its pathobiological significance. Journal of Biological Chemistry, 1997; 272:20963-20966.

Steinberg D, Witztum JL. Oxidized low-density lipoprotein and atherosclerosis. Arteriosclerosis, Thrombosis, and Vascular Biology, 2010; 30:2311-2316.

Tseng C-H. Cardiovascular disease in arsenic-exposed subjects living in the arseniasis-hyperendemic areas in Taiwan. Atherosclerosis, 2008; 199:12-18.

Yao L, Huang L, He Z, Zhou C, Li G. Occurrence of arsenic impurities in organoarsenics and animal feeds. Journal of agricultural and food chemistry, 2013; 61:320-324.

\section{How to cite this article:}

Ishola AA, Talib NA, Muhammad N, Buyong Z, Mohamed AH, Myint Y, Samsuddin N, Ghani RA, Abdullah N. Organic Arsenical Exposure Stimulates Atherosclerosis Through Oxidative Stress Increase and Adhesion Molecule Expression. J App Pharm Sci, 2016; 6 (11): 040-051. 